\title{
Farklı diyaliz modalitelerinin hasta yakını yaşam kalitesi üzerindeki etkileri
}

\section{The impact of different dialysis modalities on caregivers' quality of life}

Cenk Gökalp

Trakya Üniversitesi Tıp Fakültesi, Nefroloji Bilim Dalı, Edirne, Türkiye

\section{Öz}

Amaç: Kronik hastalığa sahip hastaların bakımlarından sorumlu olan yakınlarının bakım süreci sebebiyle fiziksel, zihinsel ve duygusal olarak etkilendikleri bilinmektedir. Bu çalışmada, hemodiyaliz ve periton diyalizi hastalarının bakımlarıyla ilgilenen yakınlarının yaşam kalitelerinin uygulanan tedavi modalitelerinden ne şekilde etkilendiği araştırıldı.

Gereç ve Yöntem: Kronik hemodiyaliz ve periton diyalizi uygulanan hastaların birincil derece bakımlarından sorumlu yakınlarının yaşam kaliteleri SF-36 sağlık anketi ile değerlendirildi.

Bulgular: Hemodiyaliz hastalarının bakımından sorumlu hasta yakınlarının fiziksel fonksiyon, fiziksel rol kısıtlaması ve duygusal rol kısıtlaması skorlarının, periton diyalizi hasta yakınları ile karşılaştırıldığında, istatistiksel olarak anlamlı bir şekilde düşük olduğu gözlendi $(p=0,002, p=0,019$, $p=0,017)$.

Sonuç: Periton diyalizi, hemodiyaliz ile karşılaştırıldığında, sadece hastalara değil aynı zamanda hasta yakınlarına da daha iyi yaşam kalitesi sağlamaktadır.

Anahtar Sözcükler: Hemodiyaliz, periton diyalizi, hasta yakını, yaşam kalitesi, SF-36.

\section{ABSTRACT}

Aim: Caregivers responsible for the care of patients with chronic disorders are affected physically, mentally, and emotionally due to the care process. In this study, we investigated the effect of hemodialysis and peritoneal dialysis modalities on the quality of life of their caregivers.

Materials and Methods: The quality of life of the caregivers responsible for primary care for patients who underwent chronic hemodialysis and peritoneal dialysis was evaluated using the SF-26 health survey.

Results: Physical function, physical role limitation, and emotional role limitation scores of hemodialysis caregivers were statistically lower compared with peritoneal dialysis caregiver's scores $(p=0.002, p=0.019, p=0.017)$.

Conclusion: Compared with hemodialysis, peritoneal dialysis provides a better quality of life not only for patients but also for their caregivers.

Keywords: Hemodialysis, peritoneal dialysis, caregiver, quality of life, SF-36.

\section{GíRiş}

Kronik böbrek hastalığı (KBH) toplumda \%9,1 sıklıkla görülmektedir ve bu hasta grubunun yaklaşık \%10'u son dönem böbrek yetmezliği (SDBY) olarak adlandırılan hastalığın son evresinde bulunmaktadır (1). Hastalığın son evresinde yaşamın devam ettirilebilmesi için renal replasman tedavilerinden (RRT) birinin tercih edilmesi gerekmektedir.

\footnotetext{
Sorumlu yazar: Cenk Gökalp

Trakya Üniversitesi Tıp Fakültesi, Nefroloji Bilim Dalı, Edirne, Türkiye

E-posta: cenkshome@yahoo.com

Başvuru tarihi: 15.09.2020 Kabul tarihi: 17.11.2020
} 
Böbrek transplantasyonu gerek hasta sağ kalımı gerekse de yaşam kalitesindeki iyileşme göz önüne alındığında en iyi RRT seçeneğini oluşturmaktadır (2). Transplantasyon imkânı bulunmayan hastalarda ise tedavi seçeneği olarak hemodiyaliz (HD) veya periton diyalizi (PD) uygulanabilmektedir. Bu iki farklı diyaliz modalitelerinin hasta sağ kalımı ve hasta yaşam kalitesi üzerindeki etkileri tartışmalıdır (3). Bu hastaların çoğunlukla ileri yaşta olması, hemodiyaliz hastalarının haftanın belirli günlerinde diyaliz merkezlerine gitmek zorunda kalması, periton diyalizi hastalarının evde sürekli diyaliz işlemini uygulamak zorunda olması ve SDBY hastalarında sık gözlenen ek hastalıklar, hastaların bakımını üstlenen hasta yakınlarını fiziksel, zihinsel ve sosyal olarak etkileyebilmektedir.

$\mathrm{Bu}$ çalışmada, iki farklı diyaliz modalitesi uygulanan hastaların birincil derecede bakımını üstlenmiş hasta yakınlarının yaşam kalitelerinin değerlendirilmesi amaçlandı.

\section{GEREÇ VE YÖNTEM}

\section{Çalışma Popülasyonu}

Çalışmamıza üçüncü basamak bir üniversite hastanesi bünyesinde $H D$ ve $P D$ ünitelerinde takip edilen kronik hastaların yakınları dahil edildi (Şekil-1). Hemodiyaliz grubunda takip edilen 35 hastanın 32 kadarında hastanın birinci derecede bakımını üstlenen hasta yakını varken, periton diyalizi grubunda takip edilen 34 hastanın 30 kadarında birincil derecede bakımını üstlenen hasta yakını mevcuttu. Çalışmamıza dahil edilme kriterleri arasında 18 yaşından büyük olmak, hastanın en az 6 aydır diyaliz programında olması ve hasta yakınının en az 6 aydır bakımdan birinci derecede sorumlu olması yer alıyordu. Dışlama kriterleri arasında hasta için gebelik ve kanser tanısının olması, hasta yakını için de çalışmaya dahil olmak istememe yer alıyordu. Hemodiyaliz hasta grubunda 2 hastanın kanser tanılarının olması sebebiyle bu hasta yakınları da dışlanarak toplam 30 hasta yakını çalışmaya dahil edildi. Çalışma protokolü ilgili üniversitenin etik kurulu komitesi tarafından onaylandı (Tarih: 14.09.2020, No: 220-337) ve çalışmaya dahil edilen bütün gönüllülerden yazılı aydınlatılmış onam formu alındı.

\section{Yaşam Kalitesinin Değerlendirilmesi}

$\mathrm{Bu}$ çalışmada hasta yakınlarının yaşam kalitelerini değerlendirmek için Medical Outcomes Study Short Form-36 (SF-36) Sağlık Anketi kullanıldı. Bu anket; fiziksel fonksiyon, sosyal fonksiyon, fiziksel rol kısıtlaması, duygusal rol kısıtlaması, zihinsel sağlık, yaşama gücü, beden ağrısı ve genel sağlık algısı olmak üzere toplam sekiz sağlık ilişkili yaşam kalitesi alanını ölçmektedir. Ölçüm için kullanılan her alanda 0 (en düşük) ile 100 (en yüksek) arasında puanlama yapılmaktadır (4). Anket formu, HD hastalarının diyalize geldikleri gün hasta yakınlarının kendileri tarafından diyaliz ünitesinde doldurulmuştur. Periton diyalizi hasta yakınlarının anketleri ise aylık değerlendirilmeleri amacıyla başvurdukları PD ünitesinde yine hasta yakınlarının kendileri tarafından doldurulmuştur. Hasta popülasyonu ve sağlıklı bireylerde yaşam kalitesi değerlendirilmesinde kullanılan bu anket Pınar ve ark. tarafından Türkçe dilinde uyarlanmıştır (5).

\section{Istatistiksel Analiz}

Çalışmada elde edilen verilerin dağılımlarının normalliğinin test edilmesi için Kolmogorov Smirnov testi uygulanmış ve veriler dağılım durumlarına göre ortalama \pm standart sapma veya ortanca (min.-maks.) olarak bildirilmiştir. İki grup arasındaki ortalamaların karşılaştııılması için Student's t-test kullanılmıştır. Normal dağılım göstermeyen verilerin analizi için non-parametrik test olarak Mann-Whitney $U$ testi uygulanmıştır. Veriler arasındaki korelasyon ilişkisinin araştırılması amacıyla Spearman korelasyon analizi uygulanmıştır. Elde edilen $p$ değerinin 0,05 'ten küçük olması istatistiksel olarak anlamlı kabul edilmiştir.

\section{BULGULAR}

$\mathrm{Bu}$ çalışmaya 30 hemodiyaliz ve 30 periton diyalizi olmak üzere toplam 60 hasta yakını dahil edilmiştir. Hemodiyaliz ve PD hastalarının demografik özellikleri Tablo-1'de gösterilmiştir. Hemodiyaliz hastalarının yaş ortalamaları PD hastalarının yaş ortalamalarından istatistiksel olarak anlamlı derecede yüksekti (62,3 vs. 55,1, $\mathrm{p}=0,029)$. Her iki hasta popülasyonu arasında cinsiyet, diyastolik kan basıncı, ortalama arter basıncı, beden kitle endeksi, komorbiditeler ve diyalize girme süreleri açısından herhangi bir fark saptanmazken, sistolik kan basıncı hemodiyaliz hasta grubunda istatistiksel olarak anlamlı derecede yüksek gözlendi. Anjiotensin dönüştürücü enzim inhibitörü veya anjiotensin reseptör blokeri kullanma sıklığı periton diyalizinde daha fazla gözlendi. Her iki hasta grubunda bunların dışındaki antihipertansif ilaç kullanımı, fosfor düşürücü ilaç kullanımı, eritropoietin ve kalsimimetik ajan kullanımı açısından herhangi bir fark saptanmadı. 
Tablo-1. Hemodiyaliz ve periton diyalizi hastalarının demografik özellikleri.

\begin{tabular}{|c|c|c|c|}
\hline & Hemodiyaliz & Periton Diyalizi & p-değeri* \\
\hline Yaş & $62,3 \pm 14,2$ & $55,1 \pm 8,7$ & 0,029 \\
\hline Cinsiyet, n (\%) & & & 0,188 \\
\hline Kadın & $9(30 \%)$ & $14(46 \%)$ & \\
\hline Erkek & $21(70 \%)$ & $16(54 \%)$ & \\
\hline \multicolumn{4}{|l|}{ Kan Basıncı, mmHg } \\
\hline Sistolik & $138,5 \pm 29,2$ & $121,7 \pm 19,6$ & 0,012 \\
\hline Diyastolik & $74,6 \pm 12,4$ & $75,5 \pm 11,1$ & 0,934 \\
\hline Ortalama Arter & $95,9 \pm 16,6$ & $90,9 \pm 13,8$ & 0,155 \\
\hline Beden Kitle Endeksi, $\mathrm{kg} / \mathrm{m}^{2}$ & $24,9 \pm 4,6$ & $25,3 \pm 4,5$ & 0,605 \\
\hline Komorbiditeler, n (\%) & & & 0,964 \\
\hline Diabetes mellitus & $8(27 \%)$ & $8(27 \%)$ & \\
\hline Hipertansiyon & $18(60 \%)$ & $19(63 \%)$ & \\
\hline KBY etiyoloji, n (\%) & & & 0,898 \\
\hline Diabetes mellitus & 7 (24\%) & $6(20 \%)$ & \\
\hline Hipertansiyon & $17(59 \%)$ & $19(63 \%)$ & \\
\hline Glomerulonefrit & $3(10 \%)$ & $5(16 \%)$ & \\
\hline Polikistik Böbrek Hastalığı & $2(7 \%)$ & $0(0 \%)$ & \\
\hline Diyaliz süresi, yıl & $5,7 \pm 4,7$ & $5,3 \pm 3,9$ & 0,887 \\
\hline \multicolumn{4}{|l|}{ Diyaliz yeterliliği } \\
\hline$K t / V$ & $1,63 \pm 0,37$ & $2,44 \pm 0,47$ & 0,000 \\
\hline$\ddot{U R R}$ & $70,6 \pm 7,7$ & - & \\
\hline \multicolumn{4}{|l|}{ Antihipertansif ilaç, $\mathrm{n}(\%)$} \\
\hline$A C E i / A R B$ & $0(0 \%)$ & $5(16 \%)$ & 0,040 \\
\hline CaCh-Bloker & $13(43 \%)$ & $11(36 \%)$ & 0,601 \\
\hline Beta-Bloker & $13(43 \%)$ & $11(36 \%)$ & 0,601 \\
\hline Alfa-Bloker & $1(3 \%)$ & $2(6 \%)$ & 0,557 \\
\hline \multicolumn{4}{|l|}{ Forfor bağlayıcı, n (\%) } \\
\hline$C A / C C$ & $16(55 \%)$ & $11(36 \%)$ & 0,198 \\
\hline Sevelamer & $12(41 \%)$ & $13(43 \%)$ & 0,795 \\
\hline Lantanyum karbonat & $1(3 \%)$ & $3(10 \%)$ & 0,305 \\
\hline Kalsimimetik, n (\%) & $2(7 \%)$ & $6(20 \%)$ & 0,132 \\
\hline EPO, n (\%) & $15(52 \%)$ & $8(26 \%)$ & 0,065 \\
\hline \multicolumn{4}{|l|}{ Biyokimya Parametreleri } \\
\hline Lökosit, $\times 10^{3} / \mu L$ & $6,61 \pm 1,63$ & $8,09 \pm 2,25$ & 0,007 \\
\hline Hemoglobin, $g / d L$ & $10,8 \pm 1,6$ & $11,5 \pm 2,1$ & 0,329 \\
\hline Hematokrit, \% & $32,3 \pm 4,9$ & $33,9 \pm 6,6$ & 0,853 \\
\hline Platelet, $x 10^{3} / \mu \mathrm{L}$ & $192,3 \pm 53,1$ & $257,6 \pm 66,4$ & 0,000 \\
\hline$C R P, m g / d L$ & $2,09 \pm 0,56$ & $0,85 \pm 0,16$ & 0,039 \\
\hline Üre, $m g / d L$ & $135,7 \pm 36,7$ & $111,9 \pm 31,1$ & 0,020 \\
\hline Kreatinin, $m g / d L$ & $9,3 \pm 2,6$ & $8,9 \pm 2,1$ & 0,496 \\
\hline $\mathrm{Na}^{+}, m E q / L$ & $137,3 \pm 3,4$ & $137,1 \pm 3,4$ & 0,893 \\
\hline$K^{+}, m E q / L$ & $5,2 \pm 0,8$ & $4,65 \pm 0,65$ & 0,002 \\
\hline $\mathrm{Ca}^{+2}, \mathrm{mg} / \mathrm{dL}$ & $8,9 \pm 1,2$ & $9,1 \pm 0,5$ & 1,000 \\
\hline $\mathrm{PO}_{4}^{-2}, \mathrm{mg} / \mathrm{dL}$ & $5,3 \pm 1,0$ & $5,6 \pm 0,9$ & 0,255 \\
\hline$P T H, p g / m L$ & $664 \pm 119$ & $627 \pm 76$ & 0,615 \\
\hline Albumin, $g / d L$ & $3,6 \pm 0,4$ & $3,5 \pm 0,3$ & 0,384 \\
\hline
\end{tabular}

$\mathrm{KBY}=$ Kronik böbrek yetmezliği, ÜRR = Üre azalma oranı, $\mathrm{ACEi}=$ Anjiotensin dönüştürücü enzim inhibitörü, $\mathrm{ARB}=\mathrm{Anjiotensin}$ reseptör blokeri, CaCh-Bloker $=$ Kalsiyum kanal blokeri, CA $=$ Kalsiyum asetat, $C C=$ Kalsiyum karbonat, EPO = Eritropoietin, $\mathrm{CRP}=\mathrm{C}$-reactive protein, $\mathrm{PTH}=$ Parathormon

*İstatistiksel olarak anlamlı olan değerler kalın yazıımıştır. 
Tablo-2. Hasta yakınlarının demografik özellikleri.

\begin{tabular}{|c|c|c|c|}
\hline & Hemodiyaliz & Periton Diyalizi & $p$-değeri* \\
\hline Yaş, yıl & $59,4 \pm 13,8$ & $52,8 \pm 11,5$ & 0,072 \\
\hline \multicolumn{4}{|l|}{ Cinsiyet, n (\%) } \\
\hline Kadın & $24(80 \%)$ & $20(67 \%)$ & 0,247 \\
\hline Erkek & $6(20 \%)$ & $10(33 \%)$ & \\
\hline \multicolumn{4}{|l|}{ Kan Basıncı, mmHg } \\
\hline Sistolik & $123,0 \pm 13,2$ & $122,3 \pm 16,7$ & 0,538 \\
\hline Diyastolik & $73,3 \pm 7,1$ & $74,2 \pm 8,7$ & 0,606 \\
\hline Ortalama Arter & $90,1 \pm 7,3$ & $90,2 \pm 9,6$ & 0,875 \\
\hline Beden Kitle Endeksi, $\mathrm{kg} / \mathrm{m}^{2}$ & $25,0 \pm 3,6$ & $29,3 \pm 5,8$ & 0,004 \\
\hline \multicolumn{4}{|l|}{ Kronik Hastalık } \\
\hline Diabetes Mellitus & $4(13 \%)$ & $0(0 \%)$ & 0,040 \\
\hline Hipertansiyon & $12(40 \%)$ & $11(36 \%)$ & 0,792 \\
\hline \multicolumn{4}{|l|}{ Eğitim Seviyesi } \\
\hline Eğitimsiz & $2(7 \%)$ & $3(10 \%)$ & 0,37 \\
\hline İlköğretim & $11(36 \%)$ & $13(43 \%)$ & \\
\hline Lise & $13(43 \%)$ & $10(33 \%)$ & \\
\hline Üniversite & $4(13 \%)$ & $4(13)$ & \\
\hline \multicolumn{4}{|l|}{ Gelir Düzeyi, n (\%) } \\
\hline$<2500$ TL/ay & $4(13 \%)$ & $3(10 \%)$ & 0,57 \\
\hline $2500-5000$ TL/ay & $23(77 \%)$ & $24(80 \%)$ & \\
\hline >5000 TL/ay & $3(10 \%)$ & $3(10 \%)$ & \\
\hline \multicolumn{4}{|l|}{ Çalışma durumu, n (\%) } \\
\hline Çalışmıyor & $19(65 \%)$ & $23(77 \%)$ & 0,18 \\
\hline Çalışıyor & 11 (35\%) & $7(23 \%)$ & \\
\hline
\end{tabular}

*-İstatistiksel olarak anlamlı olan değerler kalın yazılmıştır.

Tablo-3. Hasta yakınlarının SF-36 skorlarının karşılaştırması

\begin{tabular}{lccc}
\hline & Hemodiyaliz & Periton Diyalizi & p-değeri $^{*}$ \\
\hline Fiziksel Fonksiyon & $62,33 \pm 29,29$ & $84,17 \pm 18,25$ & $\mathbf{0 , 0 0 2}$ \\
Fiziksel Rol Kısıtlaması & $50,83 \pm 41,77$ & $74,17 \pm 35,04$ & $\mathbf{0 , 0 1 9}$ \\
Duygusal Rol Kısıtlaması & $43,33 \pm 43,90$ & $71,12 \pm 39,86$ & $\mathbf{0 , 0 1 7}$ \\
Canılık & $55,00 \pm 25,15$ & $62,33 \pm 27,75$ & 0,210 \\
Zihinsel Sağlık & $62,40 \pm 19,27$ & $66,13 \pm 25,38$ & 0,334 \\
Sosyal Fonksiyon & $66,67 \pm 27,53$ & $68,33 \pm 28,38$ & 0,620 \\
Ağrı & $69,50 \pm 25,12$ & $79,50 \pm 27,47$ & 0,056 \\
Genel sağlık & $61,50 \pm 19,08$ & $57,00 \pm 25,07$ & 0,553 \\
\hline
\end{tabular}

*- İstatistiksel anlamlı olan değerler kalın belirtilmiştir. 
Laboratuvar parametrelerinde ise lökosit ve trombosit sayıları HD hasta grubunda PD grubuna göre anlamlı derecede düşük gözlenirken, üre ve CRP düzeyleri periton diyalizi grubunda daha düşük gözlendi. Bunların yanında serum potasyum düzeyinin de periton diyalizi grubunda daha düşük olduğu gözlendi.

Hasta yakınlarının bazal demografik özellikleri Tablo-2'de gösterilmiştir. İki grup karşılaştırıldığında yaş, cinsiyet, kan basıncı ölçümleri, hipertansiyon sıklığı, eğitim düzeyi, gelir düzeyi ve çalışma durumları arasında herhangi bir fark gözlenmedi. Beden kitle endeksi periton diyalizi hasta yakınlarında hemodiyaliz hasta yakınları ile karşılaştırıldığında istatistiksel olarak anlamlı derecede yüksekti $(p=0,004)$. Bunun yanında, hemodiyaliz hasta yakınlarında diabetes mellitus sıklığı PD hasta yakınlarına göre daha yüksek gözlendi $(p=0,04)$.

Çalışmaya katılan hasta yakınlarının SF-36 sağlık anketi skorları Tablo-3'te gösterilmiştir. Elde edilen veriler incelendiğinde, periton diyalizi hasta yakınlarının fiziksel fonksiyon, fiziksel rol kısıtlaması ve duygusal rol kısıtlaması skorlarının, hemodiyaliz hasta yakınlarına göre istatistiksel olarak anlamlı düzeyde yüksek olduğu gözlendi ( $p=0,002, p=0,019, p=0,017)$. Genel sağlık dışındaki diğer sağlık konseptlerinde de periton diyalizi hasta yakınlarının skorlarının hemodiyaliz ile karşılaştırıldığında yüksek olduğu gözlendi fakat istatistiksel olarak anlamlı bir fark gözlenemedi. Hemodiyaliz hasta grubunda yaş ortalamalarının yüksek olması sebebiyle yapılan Spearman korelasyon analizinde hastaların yaşı ile hasta yakınlarının SF-36 skorları arasında herhangi bir anlamlı korelasyon gözlenmedi.

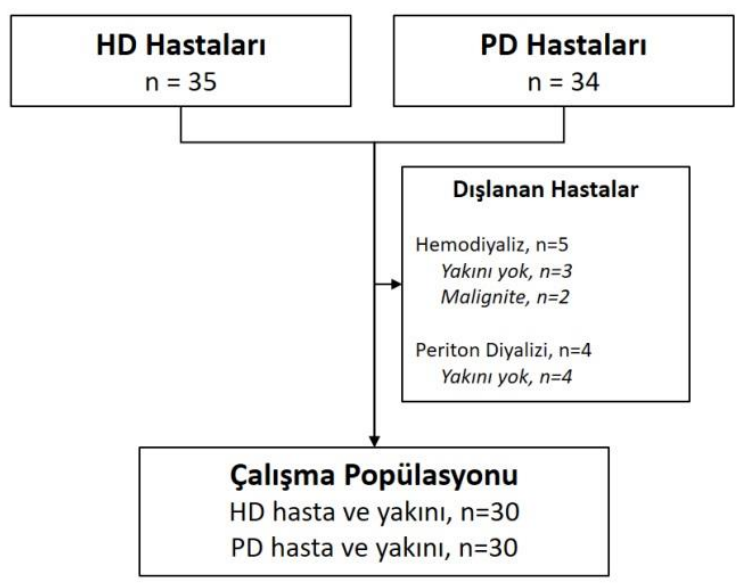

Şekil-1. Çalışmaya dahil edilen hasta dağılımı.

\section{TARTIŞMA}

Hemodiyaliz ve periton diyalizi, son dönem böbrek yetmezliği olan hastalarda yaşamın idame ettirilebilmesi için dünyada yaygın olarak kullanılan iki tedavi yöntemidir (6). Periton diyalizi tedavisi, yeterli düzeyde tedavi protokolü eğitimi almış hasta ve/veya hasta yakını tarafından hastanın evinde sürekli elle veya aletli sıvı değişimi ile yapılmaktadır. Evde tedavi yöntemlerinden biri olan periton diyalizinin uygulanabilmesi için hasta veya yakınının belirli sosyokültürel seviyede olması, sıvı değişimlerinin uygulanabileceği uygun değişim odasının olması, işlemlerin asepsi kurallarına uygun bir şekilde doktor ve hemşire reçetelerine uygun şekilde yapılabilmesi gerekmektedir. Hastalara esneklik, özgüven, hastane ortamından uzaklaşma, daha esnek kronik böbrek yetmezliği diyeti, daha iyi sağ kalım ve yaşam kalitesi imkanı sağlayan periton diyalizi tedavisi aynı zamanda her gün uygulama gerekliliği, evde hijyenik ortamın sağlanması, tedavi sorumluluğunun üstlenilmesi, sağlık personelinden uzak olunması gibi sebeplerden hasta ve hasta yakınlarına fiziksel, duygusal ve sosyal anlamda yük oluşturabilmektedir (7-11). Hemodiyaliz tedavisi ise çoğunlukla diyaliz merkezinde sağlık personeli denetiminde yapılması, haftanın belirli günlerinde uygulanması, ev ortamında herhangi bir düzenleme gerektirmemesi (ev hemodiyalizi uygulanan hastalar dışında) gibi göreceli avantajlar sağlamasının yanında haftanın belirli günlerinde bir diyaliz merkezine bağlı olma, fizyolojik olmayan kan temizleme işleminin diyaliz günlerinde hastada yarattığı halsizlik, bulantı ve kusma, kas krampları gibi yan etkilere sebep olabilmesi, kanama ve osteoporoz riskini arttıran kan sulandırıcı ilaç kullanma zorunluluğu, daha sıkı diyet ve daha fazla mortalite ve morbidite riski sebeplerinden hasta ve hasta yakınlarına yük oluşturabilmektedir (12-14).

Diyaliz tedavisi uygulanan hastaların yakınlarının yaşam kaliteleri daha önce yapılan çalışmalarda farklı ölçekler kullanılarak değerlendirilmiştir. Bardak ve ark. tarafından yapılan bir çalışmada periton diyalizi, hemodiyaliz ve böbrek nakli hastalarının dahil edildiği 127 hasta yakınına Zarit bakıcı yük ölçeği ve Belirti Tarama Listesi (SCL-90) ölçekleri uygulanmış ve HD hasta yakını grubunda bakım yükünün daha fazla olduğu gözlenmiştir (15). Belasco ve ark. yaptığı bir çalışmada $100 \mathrm{HD}$ hastası ve bunların yakınlarına bir yıllık takibin öncesinde ve 
sonrasında SF-36 sağlık anketi ve bakıcı yükü ölçeği uygulanmış ve HD hasta grubunda mental sağlık ve canlılık skorlarının daha düşük olduğu gözlenmiştir (16). Fan ve ark. tarafından yapılan bir çalışmada PD hasta yakınlarına 1 yıllık izlem öncesi ve sonrasında SF-36 yaşam ölçeği uygulanmış ve genel popülasyon ile karşılaştırıldığında daha düşük skorlara sahip oldukları gözlenmiştir (17).

Medical Outcomes Study Short Form 36 (SF-36) sağlık anketi 14 yaş üzeri bireylerin sağlık durumlarının değerlendirilmesi amacıyla RAND Corporation tarafından oluşturulmuş bir ankettir (18). SF-36 anketi ile bireylerin sekiz sağlık konsepti değerlendirilmektedir: fiziksel aktivitelerdeki kısıtlılık, fiziksel ve duygusal problemler nedeniyle sosyal aktivitelerde kısıtlılık, fiziksel problemler sebebiyle rol kısıtılıkları, duygusal problemler nedeniyle rol kısıtılığı, vücut ağrısı, genel zihinsel sağlık, canlılık ve genel sağlık algısı. Bazı çalışmalarda bu sekiz sağlık kavramının ayrı ayrı değerlendirilmek yerine toplam skor veya zihinsel ve duygusal bileşen skoru şeklinde hesaplandığı bilinmektedir, fakat bu skorlamalar anketi geliştiren firma tarafından önerilmemektedir. $\mathrm{Bu}$ nedenle bu çalışmada gönüllülerin SF-36 ölçeklerini değerlendirirken sekiz kavramı da ayrı ele alarak analiz yapıldı. Bu çalışmada HD hasta yakınlarının, duş alma veya kıyafet değiştirme gibi normal günlük fiziksel aktivitelerinin değerlendirildiği fiziksel fonksiyon skorlarının PD hasta yakınlarına göre daha düşük olduğu gözlendi. Bunun yanında fiziksel ve duygusal sağlık durumunun, günlük aktiviteler veya iş ortamı üzerindeki etkilerini değerlendiren fiziksel ve duygusal rol kısıtlıı̆g skorları da HD hasta yakınlarında anlamlı derecede düşük gözlendi. Saptanan bu farklar, iki hasta grubu arasında yaş ile ilgili anlamlı korelasyonun saptanamaması ve demografik özelliklerin birbirine benzer olduğu da göz önüne alındığında, hemodiyaliz tedavisinin periton diyalizi ile karşılaştırıldığında sadece hasta için değil aynı zamanda hasta yakını için de belirgin bir yük oluşturduğunu göstermektedir. Bu durumu, PD tedavisinin hastaya sağladığı günlük aktivitelerde daha özgür olunması, tedavide aktif rol alınması ve bunun yarattığı artmış özgüven, daha iyi sıvı ve elektrolit dengesinin sağlanması gibi pozitif etkilerinin sadece hastaya değil aynı zamanda hasta yakınına da fiziksel, duygusal ve sosyal anlamda avantaj sağlaması ile ilişkilendirebiliriz. Hemodiyaliz hasta yakınlarında genel vücut ağrısı skorları, PD yakınlarına göre istatistiksel olarak anlamlıya yakın düşük gözlendi. Bu durumun, HD hasta yakınlarında daha fazla gözlenen diabetes mellitusa bağlı olabileceği gibi bu kişilerde mevcut olan artmış fiziksel, duygusal ve sosyal yükün sebep olabileceği kaygı, depresyon veya somatizasyona bağlı olabileceği de düşünülmüştür. Bu çalışma ile, literatürde ilk defa, HD ve PD hasta yakınları arasındaki yaşam kalitesi farkı SF-36 ölçeği kullanılarak gösterilmiştir.

\section{Çalışmanın kısıtlılıkları}

Çalışmaya dahil edilen popülasyonun küçük olması, HD ve PD hastalarının yaşam kalitesi ölçeklerinin yapılarak hasta ve hasta yakını ölçekleri arasındaki olası ilişkinin analiz edilememesi bu çalışmanın başlıca kısıtılıkları arasında yer almaktadır.

\section{SONUÇ}

Hastalara daha fazla esneklik, özgüven, kararlı sıvı ve elektrolit dengesi sağlayan bir tedavi yöntemi olan periton diyalizi, hemodiyaliz ile karşılaştırıldığında, hasta yakınlarına da daha iyi yaşam kalitesi sunmaktadır.

\section{Çıkar çatışması}

Yazarlar çıkar çatışması beyan etmemektedir.

\section{Kaynaklar}

1. Carney EF. The impact of chronic kidney disease on global health. Nat Rev Nephrol. 2020; 16 (5): 251.

2. Saran R, Robinson B, Abbott KC, Agodoa LYC, Bragg-Gresham J, Balkrishnan R, et al. US Renal Data System 2018 Annual Data Report: Epidemiology of Kidney Disease in the United States. Am J Kidney Dis. 2019; 73 (3 Suppl 1): A7-A8.

3. Queeley GL, Campbell ES. Comparing Treatment Modalities for End-Stage Renal Disease: A Meta-Analysis. Am Health Drug Benefits. 2018; 11 (3): 118-27.

4. Demiral Y, Ergor G, Unal B, Semin S, Akvardar Y, Kivircik B, et al. Normative data and discriminative properties of short form 36 (SF-36) in Turkish urban population. BMC Public Health. 2006; 6: 247. 
5. Pinar R. Reliability and construct validity of the SF-36 in Turkish cancer patients. Qual Life Res. 2005; 14 (1): 259-64.

6. Ng JK, Li PK. Chronic kidney disease epidemic: How do we deal with it? Nephrology (Carlton). 2018; 23 Suppl 4: 116-20.

7. Trinh E, Chan CT, Perl J. Dialysis modality and survival: Done to death. Semin Dial. 2018; 31 (4): 315-24.

8. Tang SCW, Lai KN. Peritoneal dialysis: the ideal bridge from conservative therapy to kidney transplant. J Nephrol. 2020. 2020 Jul 11: 1-6.

9. Chuasuwan A, Pooripussarakul S, Thakkinstian A, Ingsathit A, Pattanaprateep O. Comparisons of quality of life between patients underwent peritoneal dialysis and hemodialysis: a systematic review and meta-analysis. Health Qual Life Outcomes. 2020; 18 (1): 191.

10. Jacquet S, Trinh E. The Potential Burden of Home Dialysis on Patients and Caregivers: A Narrative Review. Can J Kidney Health Dis. 2019; 6: 2054358119893335.

11. Aguiar R, Pei M, Qureshi AR, Lindholm B. Health-related quality of life in peritoneal dialysis patients: A narrative review. Semin Dial. 2019; 32 (5): 452-62.

12. Li H, Xie L, Yang J, Pang X. Symptom burden amongst patients suffering from end-stage renal disease and receiving dialysis: A literature review. Int J Nurs Sci. 2018; 5 (4): 427-31.

13. Sajadi SAM, Ebadi AP, Moradian STP. Quality of Life among Family Caregivers of Patients on Hemodialysis and its Relevant Factors: A Systematic Review. Int J Community Based Nurs Midwifery. 2017; 5 (3): 206-18.

14. Morishita S, Tsubaki A, Shirai N. Physical function was related to mortality in patients with chronic kidney disease and dialysis. Hemodial Int. 2017; 21 (4): 483-9.

15. Bardak S, Demir S, Aslan E, Turgutalp K, Celikcan HD, Dolarslan ME, et al. The other side of the coin in renal replacement therapies: the burden on caregivers. Int Urol Nephrol. 2019; 51 (2): 343-9.

16. Belasco AG, Sesso R. Burden and quality of life of caregivers for hemodialysis patients. Am J Kidney Dis. 2002; 39 (4): 805-12.

17. Fan SL, Sathick I, McKitty K, Punzalan S. Quality of life of caregivers and patients on peritoneal dialysis. Nephrol Dial Transplant. 2008; 23 (5): 1713-9.

18. Ware JE, Jr., Sherbourne CD. The MOS 36-item short-form health survey (SF-36). I. Conceptual framework and item selection. Med Care. 1992; 30 (6): 473-83. 